\title{
TAXA DE CÂMBIO DE EQUILÍBRIO E DESALINHAMENTO CAMBIAL: EVIDÊNCIAS PARA O BRASIL (1994-2011)
}

\author{
Aderbal Oliveira Damasceno* \\ Flávio Vilela Vieira ${ }^{\dagger}$
}

\begin{abstract}
Resumo
O trabalho estima a taxa de câmbio real efetiva de equilíbrio e o desalinhamento cambial para o Brasil no período de $1994 \mathrm{~T} 3$ a 2011T4. O trabalho contribui em três aspectos: i) constrói a série de taxa de câmbio real efetiva considerando os 20 principais parceiros comerciais; ii) os determinantes da taxa de câmbio real efetiva são calculados em relação àqueles dos 20 principais parceiros comerciais; iii) calcula uma medida de desalinhamento corrente e uma de desalinhamento total. As evidências indicam: sobrevalorização no período de câmbio rígido (1994T3 a 1998T4); subvalorização no período de câmbio flexível (1999T1 a 2011T4); subvalorização no período pós-crise do subprime (2008T3 a 2011T4); e uma sobrevalorização em 2011.
\end{abstract}

Palavras-chave: taxa de câmbio de equilíbrio; desalinhamento cambial; modelos VEC

\begin{abstract}
This paper estimates the equilibrium real effective exchange rate and the exchange rate misalignment for Brazil from 1994Q3 to 2011Q4. The paper contributes in three aspects: i) it calculates the real effective exchange rate series considering the twenty major trade partners; ii) the determinants of the real effective exchange rate are calculated relative to those of the twenty major trade partners; iii) it calculates a measure of current and total misalignment. The evidence indicates: overvalued exchange rate for the rigid exchange rate regime (1994Q3 to 1998Q4); undervaluation for the flexible exchange rate regime (1999Q1 to 2011Q4); undervaluation for the post subprime crisis (2008Q3 to 2011Q4) period; and an exchange rate overvaluation in 2011.
\end{abstract}

Keywords: equilibrium exchange rate; exchange rate misalignment; VEC models

JEL classification: F37; C32; O54.

DOI: http://dx.doi.org/10.11606/1980-5330/ea169439

\footnotetext{
* Instituto de Economia, Universidade Federal de Uberlândia. E-mail: damasceno@ie.ufu.br.

† Instituto de Economia, Universidade Federal de Uberlândia. E-mail: flaviovieira@ufu.br.
} 


\section{Introdução}

O objetivo deste trabalho é calcular a taxa de câmbio real efetiva de equilíbrio e o desalinhamento cambial para a economia brasileira no período de 1994T3 a 2011T4, caracterizado pela estabilização inflacionária alcançada com o Plano Real, mudança de regime cambial ocorrida a partir de janeiro de 1999 e ocorrência de várias crises financeiras, especialmente a de 2008. A relevância do estudo empírico está não apenas em se obter estimações para a magnitude do desalinhamento cambial, mas também fornecer subsídios para o debate recente sobre a ocorrência da chamada guerra cambial no período pós-crise financeira de 2008.

Na literatura teórica e empírica, existe um conjunto relativamente amplo de abordagens utilizadas para o cálculo da taxa de câmbio real efetiva de equilíbrio e do desalinhamento cambial, dentre as quais destacam-se: a abordagem da Paridade do Poder de Compra (PPC); a taxa de câmbio de equilíbrio fundamental (FEER) de Williamson (1983, 1994); a taxa de câmbio real natural (NATREX) de Stein (1994, 1995, 2002); o equilíbrio macroeconômico (IMF) de Isard \& Faruqee (1998) e Faruqee et al. (1999); e a abordagem comportamental da taxa real de câmbio (BEER) de Clark \& MacDonald (1999).

Este trabalho estima a taxa de câmbio real efetiva de equilíbrio e o desalinhamento cambial para a economia brasileira por meio da abordagem comportamental da taxa real de câmbio (BEER) de Clark \& MacDonald (1999) e contribui para a literatura empírica brasileira em três aspectos: i) constrói a série de taxa de câmbio real efetiva considerando os 20 principais parceiros comerciais; ii) os determinantes da taxa de câmbio real efetiva são calculados em relação àqueles dos 20 principais parceiros comerciais; iii) calcula uma medida de desalinhamento corrente e uma medida de desalinhamento total.

O trabalho encontra-se dividido em cinco seções, considerando esta introdução e as considerações finais. A Seção 2 apresenta as abordagens utilizadas para estimar a taxa de câmbio real efetiva de equilíbrio e o desalinhamento cambial e apresenta as evidências da literatura internacional e brasileira. A Seção 3 sistematiza os procedimentos metodológicos, apresenta a definição das variáveis e o comportamento das séries calculadas. A Seção 4 é dedicada à estimação dos modelos, cálculo da taxa de câmbio real efetiva de equilíbrio e do desalinhamento cambial para a economia brasileira.

\section{Desalinhamento Cambial: Teorias e Evidências}

\subsection{Modelos Teóricos}

A abordagem clássica para a mensuração da taxa de câmbio real de equilíbrio e cálculo de desalinhamento cambial é a Paridade do Poder de Compra (PPC). Para Rogoff (1996) há consenso na literatura empírica acerca da validade da PPC no longo prazo, mas as estimativas sugerem alta volatilidade da taxa de câmbio real no curto prazo e lenta reversão à média da taxa de câmbio real, o primeiro PPC puzzle. Conforme Taylor \& Taylor (2004), não há consenso na literatura empírica acerca da validade da PPC no longo prazo, o segundo PPC puzzle.

MacDonald (2000) e MacDonald \& Dias (2007) argumentam que a combinação de alta volatilidade da taxa de câmbio real no curto prazo e lenta reversão à média da taxa de câmbio real observada em estudos que corrobo- 
ram a PPC no longo prazo (primeiro PPC puzzle) e a ausência de consenso na literatura empírica acerca da validade da PPC no longo prazo (segundo PPC puzzle), sugerem que a PPC não é uma abordagem adequada para o cálculo da taxa de câmbio real de equilíbrio e desalinhamento cambial.

MacDonald (2000), MacDonald \& Dias (2007) e Égert et al. (2006) argumentam que a elaboração de uma abordagem adequada para a estimação da taxa de câmbio real de equilíbrio e mensuração de desalinhamento cambial necessita reconhecer explicitamente a existência de determinantes reais da taxa de câmbio real, os fundamentos, como explicação para os dois PPC puzzles. Duas abordagens reconhecem os determinantes reais da taxa de câmbio real: i) a abordagem do equilíbrio interno e externo; ii) a abordagem comportamental.

$\mathrm{Na}$ abordagem do equilíbrio interno e externo a taxa de câmbio real de equilíbrio é definida como aquela que satisfaz simultaneamente o equilíbrio interno e externo. Equilíbrio interno é considerado o nível de produto compatível com pleno emprego e baixa inflação, e a poupança líquida gerada a esse nível de produto deve ser igual ao saldo sustentável em conta corrente, que não é necessariamente zero nessa abordagem e define o equilíbrio externo. A Equação 1 capta a essência dessa abordagem:

$$
S(W)-I(X)=C A(\hat{q}, Y)=-C A P
$$

Em que $S$ é poupança, $I$ é investimento, $W, X$ e $Y$ são vetores de variáveis e $\hat{q}$ é a taxa real de câmbio compatível com o equilíbrio interno e externo. No âmbito dessa abordagem, três modelos se destacam: a taxa de câmbio de equilíbrio fundamental (FEER) de Williamson (1983, 1994); a taxa de câmbio real natural (NATREX) de Stein (1994, 1995, 2002); o equilíbrio macroeconômico (IMF) de Isard \& Faruqee (1998) e Faruqee et al. (1999). Uma característica da abordagem do equilíbrio interno e externo é a substancial estrutura normativa imposta na definição de equilíbrio interno e externo.

A abordagem comportamental da taxa real de câmbio (BEER) de Clark \& MacDonald (1999) assume a existência de determinantes reais da taxa de câmbio real, como explicação para os dois PPC puzzles. Ademais, essa abordagem não se baseia em qualquer modelo específico de taxa de câmbio, não impõe qualquer estrutura normativa e permite obter medida de taxa de câmbio real de equilíbrio e desalinhamento cambial por meio de tratamento estatístico rigoroso. Clark \& MacDonald (1999) especificam uma equação em forma reduzida para o comportamento da taxa de câmbio real:

$$
q_{t}=\beta^{\prime} Z_{t}+\tau^{\prime} T_{t}+\varepsilon_{t}
$$

Em que $Z$ é um vetor de fundamentos que tem efeitos persistentes a médio e longo prazo, $T$ é um vetor de fatores que tem efeitos a curto prazo, $\beta$ e $\tau$ são vetores de parâmetros e $\varepsilon$ é o erro aleatório. A taxa de câmbio real de equilíbrio corrente é definida como a taxa de câmbio real dada pelos valores correntes dos fundamentos:

$$
q_{t}^{\prime}=\beta^{\prime} Z_{t}
$$

O desalinhamento corrente $\left(d c_{t}\right)$ é a diferença entre o valor atual da taxa de câmbio real e a taxa de câmbio real dada pelos valores correntes dos fundamentos: 


$$
d c_{t}=q_{t}-q_{t}^{\prime}=q_{t}-\beta^{\prime} Z_{t}=\tau^{\prime} T_{t}+\varepsilon_{t}
$$

O desalinhamento total $\left(d t_{t}\right)$ é a diferença entre o valor atual da taxa de câmbio real e a taxa de câmbio real dada pelos valores de longo prazo dos fundamentos, $\bar{Z}$ :

$$
d t_{t}=q_{t}-\beta^{\prime} \bar{Z}_{t}
$$

Ao adicionar e subtrair $q_{t}^{\prime}$ do lado direito em (5), o desalinhamento total pode ser decomposto em dois componentes:

$$
d t_{t}=\left(q_{t}-q_{t}^{\prime}\right)+\left[\beta^{\prime}\left(Z_{t}-\bar{Z}_{t}\right)\right]
$$

Desde que $q_{t}-q_{t}^{\prime}=\tau^{\prime} T_{t}+\varepsilon_{t}$ seja o desalinhamento corrente dado em (4), a Equação (6) pode ser escrita como:

$$
d t_{t}=\tau^{\prime} T_{t}+\varepsilon_{t}+\left[\beta^{\prime}\left(Z_{t}-\bar{Z}_{t}\right)\right]
$$

O desalinhamento total $\left(d t_{t}\right)$ pode ser decomposto entre fatores transitórios, distúrbios aleatórios e desvios dos fundamentos de seus valores de equilíbrio. Clark \& MacDonald (1999) modelam o comportamento da taxa de câmbio real de longo prazo com base na condição de paridade descoberta da taxa de juros expressa em termos reais e ajustada para incluir um prêmio de risco:

$$
\Delta q_{t+k}^{e}=-\left(r-r_{t}^{*}\right)+\lambda_{t}
$$

A Equação (8) pode ser escrita para expressar a taxa de câmbio real de equilíbrio corrente em função da expectativa da taxa de câmbio real no período $t+k$, diferencial de taxa real de juros no período $t+k$ e prêmio de risco $\lambda_{t}$ :

$$
q_{t}=q_{t+k}^{e}-\left(r_{t}-r_{t}^{*}\right)+\lambda_{t}
$$

Se $q_{t+k}^{e}$ é interpretado como o componente sistemático ou de longo prazo da taxa de câmbio real, $\bar{q}_{t}$, então a Equação (9) pode ser escrita como:

$$
q_{t}=\bar{q}_{t}-\left(r_{t}-r_{r}^{*}\right)+\lambda_{t}
$$

Clark \& MacDonald (1999) assumem que o componente de longo prazo da taxa de câmbio real é determinado pelos fundamentos, relativos aos fundamentos dos parceiros comerciais:

$$
\bar{q}_{t}=f\left(n f a_{t}, \text { tot }_{t}, b s_{t}\right)
$$

Em que $n f a_{t}$ é ativo externo líquido, tot te é termos de troca e $b s_{t}$ é a razão entre o preço de bens não comercializáveis e comercializáveis e capita o efeito Balassa-Samuelson. Clark \& MacDonald (1999) consideram o prêmio de risco uma função da dívida pública, relativa à dívida pública dos parceiros comerciais:

$$
\lambda_{t}=f\left(\operatorname{debt}_{t} / \mathrm{debt}_{t}^{*}\right)
$$

As Equações (8)-(12) implicam que uma equação para o comportamento da taxa de câmbio real pode ser escrita como: 


$$
q_{t}=f\left(r_{t}-r_{r}^{*}, n f a_{t}, t o t_{t}, b s_{t}, \lambda_{t}\right)
$$

Essa é a taxa de câmbio real de equilíbrio comportamental. O efeito esperado de cada variável sobre a taxa de câmbio real é indicado pelo sinal de cada derivada parcial:

$$
\partial q_{t} / \partial\left(r_{t}-r_{r}^{*}\right)<0 ; \partial q_{t} / \partial n f a_{t}<0 ; \partial q_{t} / \partial t o t_{t}<0 ; \partial q_{t} / \partial b s_{t}<0 ; \partial q_{t} / \partial \lambda_{t}>0
$$

Conforme Égert et al. (2006), a estimação da taxa de câmbio real de equilíbrio comportamental procede em quatro etapas:

i) estimar a relação estatística de longo prazo entre a taxa de câmbio real, os fundamentos e as variáveis de curto prazo por meio de análise de cointegração;

ii) calcular o desalinhamento corrente. Os valores atuais dos fundamentos são substituídos na relação estimada. O desalinhamento corrente é a diferença entre o valor ajustado e atual da taxa de câmbio real;

iii) identificar os valores de longo prazo dos fundamentos. Isso pode ser feito usando as abordagens de Hodrick \& Prescott (1997) e Beveridge \& Nelson (1981);

iv) calcular o desalinhamento total. Os valores de longo prazo dos fundamentos são substituídos na relação estimada. O desalinhamento total é a diferença entre o valor ajustado e atual da taxa de câmbio real.

Nesse trabalho, a relação de longo prazo para a taxa de câmbio real é estimada por meio do Vetor de Correção de Erro (VEC) de Johansen (1995). Os valores de longo prazo dos fundamentos são calculados por meio do filtro de Hodrick \& Prescott (1997).

\subsection{Evidências Econométricas}

A literatura empírica sobre a mensuração da taxa de câmbio de equilíbrio e desalinhamento cambial será apresentada em duas etapas: primeiro, faz-se uma revisão seletiva da literatura internacional; segundo, faz-se uma revisão seletiva da literatura brasileira.

A revisão da literatura internacional está organizada de acordo com as quatro principais abordagens para a mensuração da taxa de câmbio de equilíbrio e desalinhamento cambial: taxa de câmbio de equilíbrio fundamental (FEER); taxa de câmbio real natural (NATREX); equilíbrio macroeconômico (IMF); abordagem comportamental da taxa real de câmbio (BEER).

Cline \& Williamson (2012) realizam estimações FEER para uma ampla amostra de países desenvolvidos e em desenvolvimento. Os resultados mais importantes indicam que a China continua com uma subvalorização da taxa de câmbio real em torno de 3\%, Austrália e Nova Zelândia vivenciam significativa sobrevalorização cambial, enquanto que outras economias asiáticas (Hong Kong, Malásia, Singapura e Taiwan) estão com suas moedas subvalorizadas. A zona do Euro encontra-se em uma situação de equilíbrio sob o ponto de vista da taxa de câmbio. Quanto à economia brasileira, a taxa de câmbio 
(R\$ / US\$) de 1,80 está abaixo da taxa de câmbio consistente com a estimativa FEER $(1,85)$. A conclusão final é que em 2012, ao se considerar uma soma ponderada pelo PIB dos desalinhamentos estimados, na média estes se encontram no menor valor $(2,6 \%)$ desde 2008 quando se iniciou essas estimativas FEER.

Stein (1995) aplica o modelo NATREX para a economia dos Estados Unidos durante o período de taxa de câmbio flutuante (pós 1973) em que a taxa de câmbio real é modelada como uma função da taxa de crescimento real do PIB doméstico e externo, do índice de preferência social e do diferencial de taxa de juros real. A partir da estimação de uma regressão múltipla para estimar o câmbio real de equilíbrio, o autor encontra evidências de que a taxa de câmbio real responde às mudanças na taxa de poupança e na produtividade, sendo que aumento na produtividade gera apreciação da taxa de câmbio real no longo prazo e uma redução na taxa de poupança melhora a situação da conta corrente.

Faruqee (1995) utiliza a abordagem do equilíbrio macroeconômico para investigar os determinantes de longo prazo da taxa de câmbio real dos Estados Unidos (1950 a 1990) e Japão (1951 a 1990) no pós-guerra. As evidências para o período sugerem subvalorização real para o Dólar e sobrevalorização real para o Yen. Os testes de cointegração sugerem a existência de uma relação determinística de longo prazo entre os componentes estruturais da conta corrente e de capital e a taxa de câmbio real. As evidências indicam que diferenciais de produtividade explicam grande parte da variação na tendência da taxa de câmbio real do Dólar e do Yen, sendo que para os Estados Unidos há também evidências de que o estoque de ativos externos líquidos tem impacto na taxa de câmbio real de longo prazo. Tanto para Estados Unidos quanto para Japão não há evidências de que os termos de troca afetam a trajetória de longo prazo da taxa de câmbio real.

Isard (2007) descreve seis diferentes metodologias (PPC; PPC ajustada aos efeitos Balassa-Samuelson e Penn; Abordagem do Equilíbrio Macroeconômico; Competitividade do Setor de Bens Comerciáveis; Equações Estimadas da Taxa de Câmbio; Modelos de Equilíbrio Geral) para o cálculo da taxa de câmbio de equilíbrio e aplica quatro dessas metodologias para os Estados Unidos com o objetivo de avaliar o processo de alinhamento do Dólar em 2006. De acordo com a abordagem da PPC e da PPC ajustada aos efeitos Balassa-Samuelson e Penn, o Dólar encontra-se alinhado em 2006. Ao se analisar o desempenho e os lucros do setor exportador dos EUA, também há uma constatação de que a moeda norte-americana se encontra alinhada em 2006. A abordagem do equilíbrio macroeconômico indica que a taxa de câmbio real efetiva estaria sobrevalorizada em 25\% em 2006.

Clark \& MacDonald (1999) estimam modelos BEER por meio de análise de cointegração para Japão, Alemanha e Estados Unidos com dados anuais no período de 1960-1996. Os determinantes da taxa de câmbio real efetiva são: termos de troca, ativo externo líquido, preço de bens não comercializáveis em relação a comercializáveis, dívida do governo e diferencial de juros real. Para 1990, os cálculos indicam: o Dólar está sobrevalorizado em $7 \%$ no conceito de desalinhamento corrente e subvalorizado em $1 \%$ no conceito de desalinhamento total; o Marco está subvalorizado em $2 \%$ no conceito de desalinhamento corrente e sobrevalorizado em $8 \%$ no conceito de desalinhamento total; o Yen está subvalorizado em $10 \%$ e $17 \%$, respectivamente, nos conceitos de desalinhamento corrente e total.

MacDonald \& Dias (2007) estimam modelos BEER para um conjunto de 
10 países industrializados e emergentes (Canadá, China, Alemanha, Japão, Noruega, Singapura, Suécia, Suíça, Reino Unido e Estados Unidos) no período de 1988T1-2006T1 por meio de análise de cointegração para cada país e painel para o conjunto de países. São considerados quatro determinantes da taxa de câmbio real efetiva: termos de troca, PIB per capita, exportações líquidas, diferencial de juros real. Os principais resultados das estimativas da taxa de câmbio real efetiva de equilíbrio indicam a necessidade de uma variação da taxa de câmbio real efetiva no início de 2006 entre $27 \%$ e $46 \%$ para a China (taxa de câmbio subvalorizada), de $5 \%$ a $11 \%$ para os EUA (taxa de câmbio sobrevalorizada) e ausência de desalinhamento para Alemanha e Reino Unido.

A revisão da literatura brasileira apresenta trabalhos publicados na década de 2000, especialmente aqueles com dados para o período recente. Em cada trabalho serão destacados o período da amostra, método econométrico, abordagem teórica, as variáveis utilizadas e os resultados encontrados para o período recente.

Badani \& Hidalgo (2005) estimam a taxa de câmbio de equilíbrio e desalinhamento cambial para o Brasil utilizando dados mensais para o período jul/1994 a dez/2002 utilizando como abordagem econométrica Mínimos Quadrados Ordinários. Os determinantes da taxa de câmbio real bilateral considerados são: termos de troca, investimento (\% PIB), progresso tecnológico, indicadores para a política macroeconômica e desvalorizações nominais. As evidências indicam ausência de desalinhamento cambial durante o período de câmbio rígido e subvalorização cambial durante o período de jan/1999 a $\mathrm{dez} / 2002$.

Paiva (2006) estima modelos BEER para o Brasil utilizando dados anuais para o período 1970 a 2005 por meio de análise de cointegração. São considerados cinco determinantes da taxa de câmbio real efetiva: termos de troca, preço de bens não comercializáveis em relação a comercializáveis, ativo externo líquido, dívida pública e diferencial de juros reais. Os resultados sugerem alternância entre sobrevalorização cambial e subvalorização cambial durante o período de câmbio rígido, sobrevalorização cambial de 1999 a 2002 e ausência de desalinhamento cambial de 2003 a 2005.

IEDI (2007) calcula a taxa de câmbio de equilíbrio e desalinhamento cambial para o Brasil utilizando dados trimestrais para o período $1980 \mathrm{~T} 1$ a $2006 \mathrm{~T} 4$ por meio de análise de cointegração. Os determinantes da taxa de câmbio real efetiva considerados são: termos de troca, diferencial de crescimento do PIB per capita, saldo comercial, diferencial de juros. Esse trabalho apresenta evidências de sobrevalorização cambial durante o período de câmbio rígido, subvalorização cambial no período de $1999 \mathrm{~T} 3$ a 2004T4 e sobrevalorização cambial no período de 2005T1 a 2006T4.

Lucinda \& Gala (2007) estimam modelos BEER para o Brasil com dados mensais para o período abr/1999 a ago/2006 por meio de análise de cointegração. Os determinantes da taxa de câmbio real bilateral considerados são: capacidade ociosa, abertura comercial, índice de preço ao produtor dos Estados Unidos convertido em reais, balança comercial, diferencial de juros, dívida líquida do setor público (\% PIB), preço de bens comercializáveis em relação a não comercializáveis, investimento (\% PIB), consumo do governo (\% PIB), consumo do setor privado (\% PIB), conta corrente (\% PIB), termos de troca. Existem evidências de alternância entre sobrevalorização cambial e subvalorização cambial no período de abr/1999 a jun/2005 e sobrevalorização cambial entre jul/2005 a ago/2006. 
Araujo \& Leite (2009) estimam a taxa de câmbio de equilíbrio e desalinhamento cambial para o Brasil utilizando dados trimestrais para o período 1994T4 a 2007T3 e como abordagem econométrica utiliza-se Mínimos Quadrados Ordinários. Os determinantes da taxa de câmbio real efetiva considerados no trabalho são: abertura comercial, preços externos, balança comercial/PIB, consumo do governo/PIB, termos de troca e diferencial de juros. Existem evidências de sobrevalorização cambial no período de câmbio rígido, alternância entre períodos de subvalorização cambial e sobrevalorização cambial no período de 1999 a 2002, ausência de desalinhamento cambial entre 2003 e 2004 e sobrevalorização cambial no período de 2005 T1 a 2007 T3.

Pastore et al. (2010) estimam a taxa de câmbio de equilíbrio e desalinhamento cambial para o Brasil utilizando dados mensais para o período abr/1990 a nov/2009 por meio de análise de cointegração. Os determinantes da taxa de câmbio real bilateral são termos de troca e passivo externo líquido. As evidências indicam a existência de sobrevalorização cambial no período de câmbio rígido, alternância entre períodos de subvalorização cambial e sobrevalorização cambial no período de 1999 a 2002 e ausência de desalinhamento cambial entre jan/2003 a nov/2009.

Marçal (2011) estima modelos BEER para o Brasil utilizando dados trimestrais para o período $1980 \mathrm{~T} 1$ a $2010 \mathrm{~T} 4$ por meio de análise de cointegração. Os determinantes da taxa de câmbio real efetiva considerados são: termos de troca, preço de bens comercializáveis em relação a não comercializáveis, passivo externo líquido e diferencial de juros reais. Este trabalho apresenta evidências de sobrevalorização cambial durante o período de câmbio rígido, subvalorização cambial no período de 1999 T1 a 2005T2 e sobrevalorização cambial no período de 2005T3 a 2010T4.

Os resultados apresentados para o Brasil permitem algumas considerações: i) Badani \& Hidalgo (2005), Lucinda \& Gala (2007) e Pastore et al. (2010) utilizam o conceito de taxa de câmbio real bilateral, mas os determinantes da taxa de câmbio real bilateral não são relativos àqueles do parceiro comercial, no caso os Estados Unidos; IEDI (2007) e Araujo \& Leite (2009) utilizam o conceito de taxa de câmbio real efetiva, mas não calculam/explicitam que os determinantes da taxa de câmbio real efetiva são calculados relativos àqueles dos parceiros comerciais; apenas Paiva (2006) e Marçal (2011) utilizam o conceito de taxa de câmbio real efetiva e calculam os determinantes da taxa de câmbio real efetiva relativos àqueles dos parceiros comerciais; apenas Lucinda \& Gala (2007), Paiva (2006) e Marçal (2011) explicitam a abordagem teórica utilizada; nenhum dos trabalhos apresentados calcula o desalinhamento total, apenas desalinhamento corrente. Por fim, dentre as evidências apresentadas, não há consenso sobre a existência de desalinhamento cambial para o período após 2002.

Este trabalho contribui para a literatura empírica em aspectos relevantes: utiliza a abordagem do equilíbrio comportamental da taxa de câmbio (BEER); calcula a taxa de câmbio real efetiva considerando os 20 principais parceiros comerciais; os determinantes da taxa de câmbio real efetiva são calculados relativos àqueles dos 20 principais parceiros comerciais; apresenta cálculo de desalinhamento corrente e desalinhamento total; utiliza informações até o quarto trimestre de 2011, sendo o trabalho que apresenta dados mais recentes, de acordo com a revisão da literatura apresentada. 


\section{Procedimentos Metodológicos}

\subsection{Abordagem Econométrica}

A abordagem econométrica utilizada neste trabalho é o Vetor de Correção de Erro (VEC) de Johansen (1995). Considere o vetor de variáveis $x_{t}^{\prime}$ de ordem $(n \times 1)$ :

$$
x_{t}^{\prime}=\left[q_{t},\left(r_{t}-r_{r}^{*}\right), n f a_{t}, \text { tot }_{t}, b s_{t}, \lambda_{t}\right]
$$

Considere que o vetor $x_{t}^{\prime}$ tem uma representação na forma de vetor autorregressivo, o qual inclui $\rho$ lags:

$$
x_{t}=\eta+\sum_{i=1}^{p} \Pi_{i} x_{t}+\varepsilon_{t}
$$

Em que $\eta$ é um vetor $(n \times 1)$ de termos determinísticos e $\varepsilon_{t}$ é um vetor $(n \times 1)$ de distúrbios ruído branco, com média zero e matriz de covariância $\Xi$. A equação anterior pode ser reparametrizada no Vetor de Correção de Erro (VEC):

$$
\Delta x_{t}=\eta+\sum_{i=1}^{p-1} \Phi_{i} \Delta x_{t-i}+\Pi x_{t-1}+\varepsilon_{t}
$$

Em que $\Delta$ é o operador em primeira diferença, $\Phi_{i}$ é uma matriz de coeficientes $(n \times n)$ igual a $\left(-\sum_{j=i+1}^{p} \Pi_{j}\right)$, $\Pi$ é uma matriz $(n \times n)$ igual $\left(\sum_{i=1}^{p} \Pi_{i}-I\right)$, cujo posto determina o número de vetores cointegrantes. Se $\Pi$ é de posto completo, $r=n$, ou de posto zero, $r=0$, não existirá cointegração entre os elementos de $x_{t}^{\prime}$ na relação de longo prazo.

Se $\Pi$ é de posto reduzido, $0<r<n$, então existirão matrizes $\alpha$ e $\beta,(n \times r)$, tal que $\Pi=\alpha \beta^{\prime}$, em que $\beta$ é a matriz cujas colunas são os vetores de cointegração linearmente independentes e $\alpha$ é a matriz de ajustamento, a qual indica a velocidade com a qual o sistema responde a desvios do nível de equilíbrio da taxa de câmbio real no último período.

Johansen (1988) e Johansen (1995) apresentam duas estatísticas para testar a existência de cointegração entre as variáveis contidas no vetor $x_{t}^{\prime}$. O primeiro teste baseia-se no traço da matriz estocástica $\Pi$ e testa $H_{0}:$ Posto $(\Pi) \leq r$ contra $H_{1}: \operatorname{Posto}(\Pi)>r$. O segundo teste baseia-se no máximo autovalor da matriz estocástica $\Pi$ e testa $H_{0}:$ Posto $(\Pi)=r$ contra $H_{1}:$ Posto $(\Pi)=r+1$.

\subsection{Definição das Variáveis}

Os dados utilizados neste trabalho são trimestrais e abrangem o período 1994T3 a 2011T4. As definições das variáveis e fontes de informações são apresentadas abaixo. Todos os índices têm como ano base $2005=100$.

Ponderação: Para a construção dos pesos foram considerados os 20 principais parceiros comerciais do Brasil no período de 1994T3 a 2011T4: Alemanha, Arábia Saudita, Argentina, Bélgica, Canadá, Chile, China, Coreia do Sul, Espanha, Estados Unidos, França, Holanda, Índia, Itália, Japão, México, Reino Unido, Rússia, Suíça e Venezuela. O peso do parceiro comercial $i$ no período $t$ 
$\left(w^{i t}\right)$ foi calculado como a razão entre o comércio total do parceiro comercial $i$ no período $t$ com o Brasil $\left((E X P+I M P)_{i t}\right)$ e o comércio total dos 20 parceiros comerciais com o Brasil no período $t\left((E X P+I M P)_{t}\right)$ :

$$
w^{i t}=(E X P+I M P)_{i t} /(E X P+I M P)_{t}
$$

A fonte de informações para o cálculo dos pesos é Direction of Trade Statistics (IMF 2013a). Os pesos variam entre os parceiros comerciais e ao longo do tempo, o que é adequado para refletir a mudança na estrutura de comércio e captar o comportamento da taxa de câmbio real efetiva e dos fundamentos econômicos relativos do Brasil. O comércio dos 20 parceiros comerciais representa em média 74,92\% do comércio total do Brasil, com mínimo de 69,72\% em 2008T4 e máximo de 79,75\% em 1999T1.

Taxa de Câmbio Real Efetiva (REER): É a média ponderada das taxas de câmbio reais bilaterais do Brasil em relação aos 20 parceiros comerciais:

$$
R E E R=\prod_{i=1}^{20}\left(\frac{S^{i} P_{c p i}^{i}}{P_{c p i}^{b}}\right)^{w^{i}}
$$

Em que $S^{i}$ é a taxa de câmbio nominal do Real em relação à moeda do parceiro comercial $i, P_{c p i}^{i}$ é o índice de preço ao consumidor do parceiro comercial $i, P_{c p i}^{b}$ é o índice de preço ao consumidor do Brasil, e $w^{i}$ são os pesos. Da forma como definida, um aumento no valor da taxa de câmbio real efetiva significa uma depreciação. A fonte de informações é International Financial Statistics (IMF 2013c). A fonte de informações para o índice de preço ao consumidor do Chile no período de $1994 \mathrm{~T} 3$ a 2011T4 é Banco Central do Chile (2013). A fonte de informações para o índice de preço ao consumidor da China no período de 1994T3 a 2011T4 é China Statistical Yearbook (2013). A fonte de informações para o cálculo da taxa de câmbio nominal dos países da zona do euro no período de 1999T1 a 2011T2 é European Central Bank (2013).

Termos de Troca (TOT): É a razão entre o índice de preço de exportação e índice de preço de importação no Brasil, relativa à média ponderada da razão entre índice de preço de exportação e índice de preço de importação dos 20 parceiros comerciais:

$$
\mathrm{TOT}=\frac{P_{x}^{b} / P_{m}^{b}}{\prod_{i=1}^{20}\left(P_{x}^{i} / P_{m}^{i}\right)^{w^{i}}}
$$

Em que $P_{x}^{b}$ é o índice de preço de exportação do Brasil, $P_{m}^{b}$ é o índice de preço de importação do Brasil, $P_{x}^{i}$ é o índice de preço de exportação do parceiro comercial $i$ e $P_{m}^{i}$ é o índice de preço de importação do parceiro comercial $i$. A fonte de informações para os índices de preço de exportação e importação é World Bank (2013). A fonte de informações para o índice de preço de importação da Suíça no período de 1994 T3 a 2011T4 é International Financial Statistics (IMF 2013c). 
Balassa-Samuelson (BS): É a razão entre o índice de preço ao consumidor e índice de preço ao atacado ou produtor do Brasil, relativa à média ponderada da razão entre o índice de preço ao consumidor e índice de preço ao atacado ou produtor dos 20 parceiros comerciais:

$$
B S=\frac{P_{c p i}^{b} / P_{p p i}^{b}}{\prod_{i=1}^{20}\left(P_{c p i}^{i} / P_{p p i}^{i}\right)^{w^{i}}}
$$

Em que $P_{c p i}^{b}$ é o índice de preço ao consumidor do Brasil, $P_{p p i}^{b}$ é o índice de preço ao atacado ou produtor do Brasil, $P_{c p i}^{i}$ é o índice de preço ao consumidor do parceiro comercial $i$ e $P_{p p i}^{i}$ é o índice de preço ao atacado ou produtor do parceiro comercial $i$. A fonte de informações para o índice de preço ao consumidor e índice de preço ao atacado ou produtor é International Financial Statistics (IMF 2013c). A fonte de informações para o índice de preço ao consumidor do Chile no período de 1994T3 a 2011T4 é o Banco Central do Chile (2013). A fonte de informações para o índice de preço ao consumidor e índice de preço ao atacado ou produtor da China no período de $1994 \mathrm{~T} 3$ a $2011 \mathrm{~T} 4$ é China Statistical Yearbook (2013). A fonte de informações para uma proxy do índice de preço ao atacado ou produtor da França no período de $1994 \mathrm{~T} 3$ a 2011T4 é OECD (2013). A fonte de informações para uma proxy do índice de preço ao atacado ou produtor da Rússia no período de $1998 \mathrm{~T} 1$ a $2011 \mathrm{~T} 4$ é $\operatorname{OECD}(2013)^{1}$.

Ativo Externo Líquido (NFA): É a diferença entre o estoque total de ativos e estoque total de passivos, como porcentagem do PIB:

$$
N F A=\frac{A T-P T}{P I B}
$$

Em que $A T$ é o estoque de ativos, PT é o estoque de passivos e PIB é o PIB brasileiro. A fonte de informações para os estoques de ativos e passivos externos do Brasil no período de 1994T3 a 2011T4 são dados anuais até 2010 disponibilizados por Lane \& Milesi-Ferretti (2007), versão atualizada, e dados anuais para 2011 de International Financial Statistics (IMF 2013c). A fonte de informações para o PIB é IMF (2013d). Os dados anuais foram interpolados para a obtenção da série trimestral.

Dívida Pública (DÍVIDA): É a dívida bruta do setor público do Brasil como porcentagem do PIB, relativa à média ponderada da dívida bruta do setor público dos 20 parceiros comerciais:

$$
D I V I D A=\frac{D^{b}}{\prod_{i=1}^{20}\left(D^{i}\right)^{w^{i}}}
$$

\footnotetext{
${ }^{1}$ Uma medida comumente utilizada para captar o efeito Balassa-Samuelson é o preço dos bens não comercializáveis em relação ao preço dos bens comercializáveis, para a qual utiliza-se como proxy a razão entre o índice de preço ao consumidor e o índice de preço ao atacado ou produtor. A justificativa para utilizar a razão entre o índice de preço ao consumidor e o índice de preço ao atacado ou produtor como proxy para a razão entre o preço dos bens não comercializáveis e preço dos bens comercializáveis é a maior participação de bens não comercializáveis no índice de preço ao consumidor e de bens comercializáveis no índice de preço ao atacado ou produtor (Kakkar \& Ogaki 1994, Faruqee 1995, Alberola et al. 1999, Clark \& MacDonald 1999, 2004, Égert et al. 2006, Bénassy-Quéré et al. 2011, Chen 2009).
} 
Em que $D^{b}$ é a dívida bruta do setor público como porcentagem do PIB do Brasil e $D^{i}$ é a dívida bruta do setor público como porcentagem do PIB do parceiro comercial $i$. A fonte de informações dos dados é Historical Public Debt Database (IMF 2013b). Os dados anuais foram interpolados para a obtenção das séries trimestrais.

Diferencial de Juros (DIFJUROS): É a diferença entre a taxa real de juros do Brasil e a média ponderada da taxa real de juros dos parceiros comerciais:

$$
\text { DIFJUROS }=r^{b}-\prod_{i=1}^{13}\left(r^{i}\right)^{w^{i}}
$$

Em que $r^{b}$ é a taxa real de juros do Brasil e $r^{i}$ é a taxa real de juros do parceiro comercial $i$. A taxa real de juros foi calculada como a diferença entre a taxa nominal de juros (Money Market Rate) e a taxa de inflação mensurada pelo índice de preço ao consumidor. Dada a limitação de informações, apenas 12 parceiros comerciais foram considerados: Argentina, Canadá, Alemanha, Itália, Japão, Coreia, México, Rússia, Espanha, Suíça, Reino Unido, Estados Unidos. A fonte de informações é International Financial Statistics $\operatorname{IMF}(2013 c)$.

As Figuras 1.a) a 1.f) mostram o comportamento das seis séries: Taxa de Câmbio Real Efetiva, Termos de Troca, Balassa-Samuelson, Ativo Externo Líquido, Dívida Pública e Diferencial de Juros para o período 1994 T3 a 2011 T4.

\section{Estimação e Resultados}

\subsection{Testes de Estacionariedade}

A avaliação da ordem de integração das séries foi feita inicialmente por meio da utilização dos testes de raiz unitária Augmented Dickey-Fuller (ADF), PhillipsPerron (PP), Kwiatkowski-Phillips-Schmidt-Shin (KPSS) e Dickey-Fuller GLS (DF-GLS). No entanto, Perron (1989) destaca que testes como o ADF pode falhar em rejeitar uma falsa raiz unitária em função de problemas de especificação da tendência determinística ${ }^{2}$

A Tabela 1 sistematiza os testes de raiz unitária ADF, PP, KPSS e DFGLS para as séries utilizadas na análise empírica para o período de 1994T3 a 2011T4. Os testes indicam que as séries ln REER, ln BS, ln TOT, NFA e ln DÍVIDA são não estacionárias em pelo menos três dos quatro testes realizados, enquanto a variável DIFJUROS é estacionária nos testes ADF, PP e KPSS, e apenas no teste DF-GLS é não estacionária. Ademais, considerando o teste DF-GLS todas as séries são não estacionárias.

\subsection{Estimação do Vetor de Correção de Erros (VEC)}

Foram estimados dois modelos VEC para a economia brasileira: o primeiro, denominado modelo sem DIFJUROS, inclui as variáveis ln REER, ln BS, ln DÍVIDA, In TOT e NFA; o segundo, denominado modelo com DIFJUROS, inclui as variáveis ln REER, ln BS, ln DÍVIDA, ln TOT, NFA e DIFJUROS.

\footnotetext{
${ }^{2}$ Perron $(1989,1997)$ e Zivot \& Andrews (2002) ampliaram o teste ADF ao considerar quebras exógenas e endógenas para evitar tal problema de especificação.
} 
Figura 1: O comportamento das seis séries

a) Taxa de Câmbio Real Efetiva

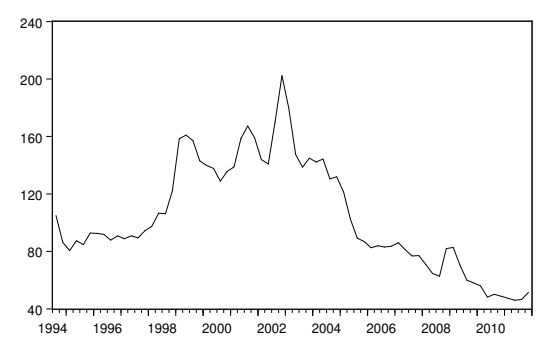

c) Balassa-Samuelson

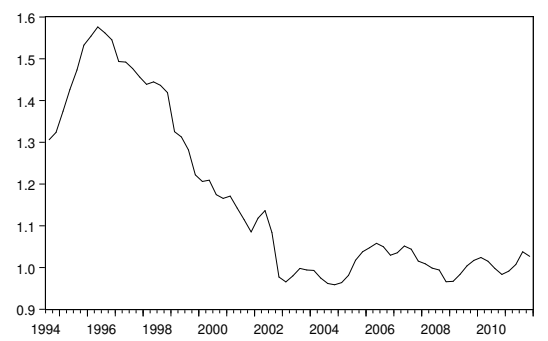

e) Dívida Pública

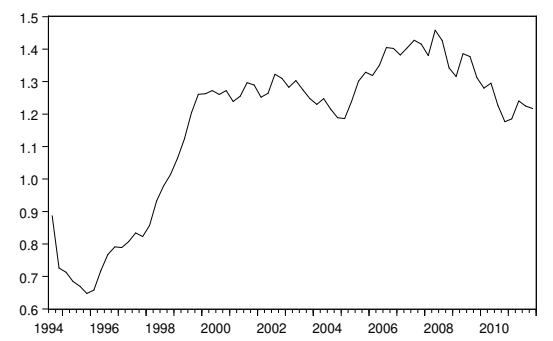

b) Termos de Troca

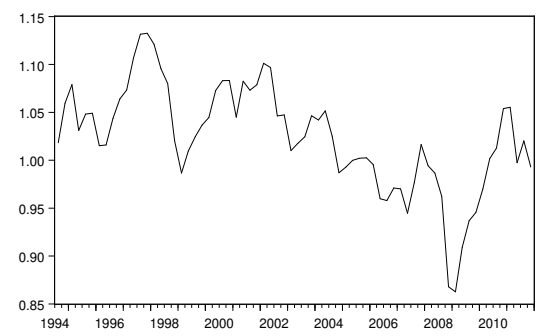

d) Ativo Externo Líquido

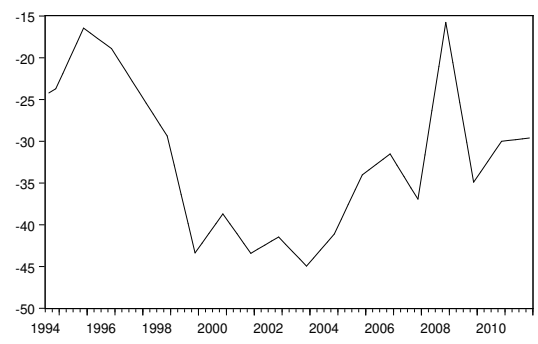

f) Diferencial de Juros

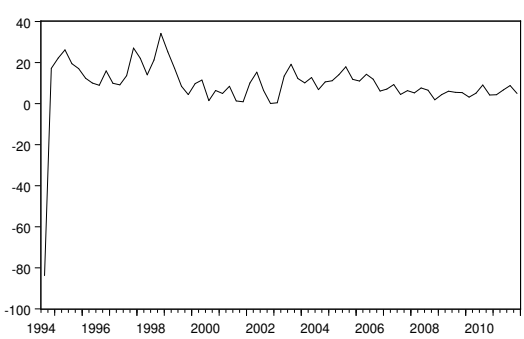

Fonte: Elaboração dos autores.

Os testes para a escolha do número de defasagens realizados por meio da estimação de um VAR com as variáveis em primeira diferença (estacionárias), conforme apresentado na Tabela 2 abaixo, indicaram a escolha de uma defasagem para o modelo sem DIFJUROS em quatro dos cinco critérios, e com duas defasagens para o modelo com DIFJUROS em três dos cinco critérios. Assim sendo, foi estimado um VEC(1) para o modelo sem DIFJUROS e um VEC(2) para o modelo com DIFJUROS ${ }^{3}$.

Os testes de cointegração (Tabelas 3 e 4) no VEC(1) para o modelo sem DIFJUROS e no VEC(2) para o modelo com DIFJUROS indicam a presença de dois vetores cointegrantes pela estatística do Traço e um vetor cointegrante pela estatística do Máximo Autovalor. Os valores obtidos para o desalinhamento cambial utilizando-se dois vetores cointegrantes não se mostraram plausíveis com magnitudes muito amplas e que fazem pouco sentido. Assim sendo, o cál-

\footnotetext{
${ }^{3}$ A escolha da especificação do modelo indica que deve ser incluída uma tendência, mas sem a constante na equação cointegrante, e sem intercepto no VAR, tanto no VEC(1) para o modelo sem DIFJUROS como no VEC(2) para o modelo com DIFJUROS.
} 
Tabela 1: Testes de estacionariedade das séries de tempo - ADF, PP, KPSS e DF-GLS

\begin{tabular}{|c|c|c|c|c|c|c|}
\hline \multicolumn{7}{|c|}{ Testes de Estacionariedade - ADF e PP } \\
\hline $\begin{array}{c}\text { Variáveis / } \\
\text { Testes }\end{array}$ & $\mathrm{ADF}$ & $\left|\begin{array}{c}\text { Ordem de } \\
\text { Integração }\end{array}\right|$ & $\begin{array}{c}\text { Defasagens ou } \\
\text { Bandwidth }\end{array}$ & PP & $\left|\begin{array}{l}\text { Ordem de } \\
\text { Integração }\end{array}\right|$ & $\begin{array}{c}\text { Defasagens ou } \\
\text { Bandwidth }\end{array}$ \\
\hline $\begin{array}{c}\text { In REER } \\
\ln \text { BS } \\
\ln \text { TOT } \\
\text { NFA } \\
\text { ln DIVIDA } \\
\text { DIFJUROS }\end{array}$ & $\begin{array}{l}-1,481 \mathrm{a} \\
-1,622 \mathrm{c} \\
-3,389 \mathrm{a} \\
-3,223^{*} \mathrm{~b} \\
-3,990^{* *} \mathrm{~b} \\
-4,833^{* *} \mathrm{a}\end{array}$ & $\begin{array}{l}\mathrm{I}(1) \\
\mathrm{I}(1) \\
\mathrm{I}(1) \\
\mathrm{I}(1) \\
\mathrm{I}(0) \\
\mathrm{I}(0)\end{array}$ & $\begin{array}{l}2 \\
2 \\
1 \\
9 \\
4 \\
2\end{array}$ & \begin{tabular}{|c|}
$-0,888 c$ \\
$-1,248 c$ \\
$-3,196 \mathrm{a}$ \\
$-0,236 \mathrm{c}$ \\
$-0,812 \mathrm{c}$ \\
$-12,944^{* *} \mathrm{a}$
\end{tabular} & $\begin{array}{l}\mathrm{I}(1) \\
\mathrm{I}(1) \\
\mathrm{I}(1) \\
\mathrm{I}(1) \\
\mathrm{I}(1) \\
\mathrm{I}(0)\end{array}$ & $\begin{array}{l}5 \\
3 \\
2 \\
3 \\
4 \\
4 \\
4\end{array}$ \\
\hline \multicolumn{7}{|c|}{ Testes de Estacionariedade - KPSS e DF-GLS } \\
\hline $\begin{array}{c}\text { Variáveis / } \\
\text { Testes }\end{array}$ & KPSS & $\left|\begin{array}{c}\text { Ordem de } \\
\text { Integração }\end{array}\right|$ & $\begin{array}{c}\text { Defasagens ou } \\
\text { Bandwidth }\end{array}$ & DF-GLS & $\left|\begin{array}{c}\text { Ordem de } \\
\text { Integração }\end{array}\right|$ & $\begin{array}{c}\text { Defasagens ou } \\
\text { Bandwidth }\end{array}$ \\
\hline $\begin{array}{c}\ln \text { REER } \\
\ln \text { BS } \\
\ln \text { TOT } \\
\text { NFA } \\
\text { ln DÍVIDA } \\
\text { DIFJUROS }\end{array}$ & $\begin{array}{l}0,261^{* *} \mathrm{a} \\
0,203^{*} \mathrm{a} \\
0,096 \mathrm{a} \\
0,235^{* *} \mathrm{a} \\
0,225^{* *} \mathrm{a} \\
0,199 \mathrm{~b}\end{array}$ & $\begin{array}{l}\mathrm{I}(1) \\
\mathrm{I}(0) \\
\mathrm{I}(0) \\
\mathrm{I}(1) \\
\mathrm{I}(1) \\
\mathrm{I}(0)\end{array}$ & $\begin{array}{l}6 \\
6 \\
5 \\
6 \\
6 \\
0\end{array}$ & $\begin{array}{l}-1,222 \mathrm{a} \\
-1,376 \mathrm{a} \\
-3,117 \mathrm{a} \\
-2,369 \mathrm{a} \\
-2,322 \mathrm{a} \\
-1,835 \mathrm{a}\end{array}$ & $\begin{array}{l}\text { I(1) } \\
\mathrm{I}(1) \\
\mathrm{I}(1) \\
\mathrm{I}(1) \\
\mathrm{I}(1) \\
\mathrm{I}(1)\end{array}$ & $\begin{array}{l}2 \\
2 \\
1 \\
9 \\
5 \\
2\end{array}$ \\
\hline
\end{tabular}

Notas: ADF, PP e DF-GLS estatística t e KPSS estatística LM. Hipótese nula para ADF, PP e DF-GLS = série possui raiz unitária. Hipótese nula para KPSS = série é estacionária. ${ }^{*} \mathrm{e}^{* *}$ indicam rejeição da hipótese nula a 5\% e $1 \%$ respectivamente. I(1) indica integrada de ordem um e não estacionária; $\mathrm{I}(0)$ indica integrada de ordem zero e estacionária. $\mathrm{a}=$ indica com constante e tendência. $\mathrm{b}=$ indica com constante e sem tendência. $\mathrm{c}=$ sem constante e tendência. A avaliação final da ordem de integração foi feita com o nível de significância de $1 \%$ quando houve rejeição de Ho apenas a $5 \%$. ADF e DF-GLS = número de defasagens com base na seleção automática pelo critério de Schwarz (SIC) - máximo de 10 defasagens. PP e KPSS = Bandwidth selecionada com base na seleção automática de Newey-West usando Bartlett Kernel.

Tabela 2: Escolha do número de defasagens - máximo de três - modelo com e sem DIFJUROS

\begin{tabular}{cccccc}
\hline \multicolumn{7}{c}{ Modelo sem DIFJUROS } \\
\hline Defasagem & LR & FPE & AIC & SC & HQ \\
\hline 1 & 97,55961 & $4,31 \mathrm{e}-12^{*}$ & $-11,98325^{*}$ & $-10,98795^{*}$ & $-11,58996^{*}$ \\
2 & 38,90408 & $4,59 \mathrm{e}-12$ & $-11,93302$ & $-10,10831$ & $-11,21199$ \\
3 & $38,16292^{*}$ & $4,72 \mathrm{e}-12$ & $-11,93870$ & $-9,28457$ & $-10,88993$ \\
\hline \multicolumn{7}{c}{ Modelo com DIFJUROS } \\
\hline 1 & 113,00280 & $1,18 \mathrm{e}-10$ & $-5,836556$ & $-4,443139^{*}$ & $-5,285951^{*}$ \\
3 & $66,46734^{*}$ & $1,03 \mathrm{e}-10^{*}$ & $-5,999748^{*}$ & $-3,411974$ & $-4,977195$ \\
& 48,52409 & $1,17 \mathrm{e}-10$ & $-5,941266$ & $-2,159135$ & $-4,446766$ \\
\hline
\end{tabular}

* Indica a ordem de defasagem escolhida por cada um dos critérios. 
culo do desalinhamento (corrente e total) foi feito a partir da estimação dos dois modelos VEC com um vetor cointegrante ${ }^{4}$.

Tabela 3: Número de equações cointegrantes - estatísticas do traço e máximo autovalor - modelo sem DIFJUROS

\begin{tabular}{ccccc}
\hline $\begin{array}{c}\text { Hipótese Testada: } \\
\text { Número de Equações } \\
\text { Cointegrantes }\end{array}$ & Autovalor & $\begin{array}{c}\text { Estatística do } \\
\text { Traço }\end{array}$ & $\begin{array}{c}\text { Valor } \\
\text { Crítico a 5\% }\end{array}$ & Prob. $^{* *}$ \\
\hline Zero * & 0,406282 & 93,66034 & 76,97277 & 0,0016 \\
Máximo de 1 * & 0,304048 & 58,20850 & 54,07904 & 0,0205 \\
Máximo de 2 & 0,209681 & 33,56027 & 35,19275 & 0,0742 \\
Máximo de 3 & 0,155104 & 17,55863 & 20,26184 & 0,1130 \\
Máximo de 4 & 0,085770 & 06,09776 & 09,16454 & 0,1833 \\
\hline Hipótese Testada: & Estatística do & Valor & Prob.** \\
Número de Equações & Autovalor & Máximo & Crítico a 5\% & \\
Cointegrantes & & Autovalor & & \\
\hline Zero * & 0,406282 & 35,45184 & 34,80587 & 0,0418 \\
Máximo de 1 & 0,304048 & 24,64824 & 28,58808 & 0,1471 \\
Máximo de 2 & 0,209681 & 16,00163 & 22,29962 & 0,2981 \\
Máximo de 3 & 0,155104 & 11,46087 & 15,89210 & 0,2195 \\
Máximo de 4 & 0,085770 & 06,09776 & 09,16454 & 0,1833 \\
\hline
\end{tabular}

* Indica rejeição da hipótese nula ao nível de 5\%. ${ }^{* *}$ MacKinnon et al. (1999)

valor-p.

A estimação do VEC(1) para o modelo sem DIFJUROS e do VEC(2) para o modelo com DIFJUROS com as especificações acima descritas produziram os seguintes coeficientes normalizados da equação cointegrante (Tabela 5). Para o modelo sem DIFJUROS, os coeficientes da equação cointegrante são significativos para as variáveis Balassa-Samuelson (ln BS) e Ativo Externo Líquido (NFA), mas não para as demais variáveis. Já para o modelo com DIFJUROS os coeficientes da equação cointegrante são significativos para as variáveis Balassa-Samuelson (ln BS), Dívida Pública (ln DÍVIDA) e Termos de Troca (ln TOT), e não significativos para Ativo Externo Líquido (NFA) e Diferencial de Juros (DIFJUROS). Os coeficientes estimados reportados na Tabela 5 possuem sinais negativos para ln BS, In DIVIDA e DIFJUROS, positivo para NFA, mas próximo de zero, e ocorre inversão de sinal para ln TOT que é positivo no modelo sem DIFJUROS e passa a ser negativo no modelo com DIFJUROS. Coeficientes estimados negativos indicam que aumentos (diminuições) nas respectivas variáveis estão associados a uma variação negativa (positiva) na taxa de câmbio real efetiva, ou seja, apreciações (depreciações) cambiais.

\footnotetext{
${ }^{4}$ Conforme (Enders 2004, p. 354): "The results of the $\lambda_{\text {trace }}$ and $\lambda_{\text {max }}$ tests can conflict. The $\lambda_{\max }$ test has the sharper alternative hypothesis. It is usually preferred for trying to pin down the number of cointegrating vectors". Foi realizado o teste LM para detecção de correlação serial com 12 defasagens e as estatísticas do teste LM (Chi-Quadrado) com 25 graus de liberdade para o modelo sem DIFJUROS e com 36 graus de liberdade para o modelo com DIFJUROS não indicam a presença de autocorrelação nos resíduos dos modelos VEC estimados, com exceção das duas primeiras defasagens do modelo com DIFJUROS. Além disso, foram realizados os testes de estabilidade (Raízes Autoregressivas - AR Roots) e de Normalidade dos resíduos, sendo que o teste de Raízes Autoregressivas confirma a estabilidade dos dois modelos VEC estimados, enquanto o teste de Normalidade indica que os resíduos dos dois modelos VEC não possuem distribuição Normal. Os resultados dos testes não foram reportados por questões de limitação de espaço, mas podem ser solicitados junto aos autores.
} 
Tabela 4: Número de equações cointegrantes - estatísticas do traço e máximo autovalor - modelo com DIFJUROS

\begin{tabular}{ccccc}
\hline $\begin{array}{c}\text { Hipótese Testada: } \\
\text { Número de Equações } \\
\text { Cointegrantes }\end{array}$ & Autovalor & $\begin{array}{c}\text { Estatística do } \\
\text { Traço }\end{array}$ & $\begin{array}{c}\text { Valor } \\
\text { Crítico a 5\% }\end{array}$ & Prob.** \\
\hline Zero * & 0,533368 & 133,29520 & 103,84730 & 0,0001 \\
Máximo de 1 & 0,348147 & 82,22679 & 76,97277 & 0,0188 \\
Máximo de 2 & 0,274275 & 53,55508 & 54,07904 & 0,0557 \\
Máximo de 3 & 0,208478 & 32,07596 & 35,19275 & 0,1044 \\
Máximo de 4 & 0,144815 & 16,41151 & 20,26184 & 0,1560 \\
Máximo de 5 & 0,084707 & 05,93022 & 09,16454 & 0,1962 \\
\hline Hipótese Testada: & & Estatística do & Valor & Prob.** \\
Número de Equações & Autovalor & Máximo & Crítico a 5\% & \\
Cointegrantes & & Autovalor & & \\
\hline Zero * & 0,533368 & 51,06841 & 40,95680 & 0,0027 \\
Máximo de 1 & 0,348147 & 28,67171 & 34,80587 & 0,2247 \\
Máximo de 2 & 0,274275 & 21,47911 & 28,58808 & 0,3075 \\
Máximo de 3 & 0,208478 & 15,66445 & 22,29962 & 0,3227 \\
Máximo de 4 & 0,144815 & 10,48129 & 15,89210 & 0,2925 \\
Máximo de 5 & 0,084707 & 05,93022 & 09,16454 & 0,1962 \\
\hline
\end{tabular}

* Indica rejeição da hipótese nula ao nível de 5\%. ${ }^{* *}$ MacKinnon et al. (1999)

valor-p.

Tabela 5: Coeficientes normalizados da equação cointegrante - modelo sem diferencial de juros

\begin{tabular}{cccccc}
\hline \multicolumn{7}{c}{ Modelo sem DIFJUROS } \\
\hline ln REER & ln BS & ln DÍVIDA & ln TOT & NFA & DIFJUROS \\
1.000 & $-4,451$ & $-0,756$ & 0,380 & $\mathbf{0 , 0 5 7}$ & \\
& $(-5,033)$ & $(-1,219)$ & $(0,215)$ & $(4,788)$ & \\
\hline \multicolumn{5}{c}{ Modelo com DIFJUROS } \\
\hline 1.000 & $-4,550$ & $-2,202$ & $-7,152$ & 0,016 & $-0,016$ \\
& $(-4,470)$ & $(-2,973)$ & $(-3,441)$ & $(1,153)$ & $(-1,215)$ \\
\hline
\end{tabular}

Nota: t-estatístico entre parênteses. A equação cointegrante inclui uma constante nos dois modelos estimados. 
Quanto aos coeficientes de ajustamento (Tabela 6) que captam o papel das variações em cada uma das variáveis dos modelos estimados na correção do erro, percebe-se que a Taxa de Câmbio Real Efetiva (ln REER), BalassaSamuelson (ln BS) e Ativo Externo Líquido (NFA) são estatisticamente significativas no modelo sem DIFJUROS, enquanto que no modelo com DIFJUROS a significância está associada a Taxa de Câmbio Real Efetiva (ln REER) e Ativo Externo Líquido (NFA).

Tabela 6: Coeficientes da matriz de ajustamento - correção de erro

\begin{tabular}{cccccc}
\hline \multicolumn{7}{c}{ Modelo sem DIFJUROS } \\
\hline D(ln REER) & D(ln BS) & D (ln DÍVIDA) & D(ln TOT) & D(NFA) & D(DIFJUROS) \\
$-0,112$ & 0,017 & $-0,013$ & $-0,0007$ & $-1,372$ & \\
$(-3,978)$ & $(-2,437)$ & $(-1,208)$ & $(-0,074)$ & $(-2,509)$ & \\
\hline \multicolumn{7}{c}{ Modelo com DIFJUROS } \\
\hline$-0,094$ & 0,0007 & $-0,009$ & 0,003 & $-0,929$ & $-1,530$ \\
$(-4,670)$ & $(0,115)$ & $(-1,102)$ & $(0,481)$ & $(-1,916)$ & $(-0,973)$ \\
\hline
\end{tabular}

Nota: t-estatístico entre parênteses.

\subsection{Análise de Desalinhamento Cambial}

\section{Desalinhamento Corrente}

A Figura 2 apresenta o comportamento da taxa de câmbio real efetiva corrente e da taxa de câmbio de equilíbrio obtida a partir da estimativa do VEC(1) para o modelo sem DIFJUROS e a Figura 3 apresenta o comportamento do desalinhamento cambial corrente associado. Os resultados sugerem: para o período 1995T1 a 1998T4 (câmbio rígido), o desalinhamento corrente médio foi de $-5,5 \%$, indicando sobrevalorização cambial; para o período após 1999T1 (câmbio flexível), o desalinhamento médio é de 1,7\%, indicando pequena subvalorização cambial; para o período após 2008T3 (crise financeira), o desalinhamento médio é $4,4 \%$, indicando subvalorização cambial; e para 2011, o desalinhamento médio é $-1,3 \%$, indicando pequena sobrevalorização cambial.

A Figura 4 apresenta o comportamento da taxa de câmbio real efetiva corrente e da taxa de câmbio de equilíbrio obtida a partir da estimativa do VEC(2) para o modelo com DIFJUROS e a Figura 5 apresenta o comportamento do desalinhamento cambial corrente associado. Os resultados sugerem: para o período 1995T2 a 1998T4 (câmbio rígido) o desalinhamento corrente médio foi de $-12,39 \%$, indicando sobrevalorização cambial; para o período após 1999T1 (câmbio flexível) o desalinhamento médio é de 5,98\%, indicando subvalorização cambial; para o período após $2008 \mathrm{~T} 3$ (crise financeira) o desalinhamento médio é 10,2\%, indicando subvalorização cambial; e para 2011 o desalinhamento médio é $-3,49 \%$, indicando pequena sobrevalorização cambial.

A Tabela 7 sintetiza os resultados apresentados considerando quatro subperíodos: o período de câmbio rígido, período de câmbio flutuante, período pós-crise do subprime e o ano 2011. Considerando o conceito de desalinhamento cambial corrente, os resultados apresentados sugerem a existência de sobrevalorização cambial durante o período de câmbio rígido e evidência de 
Figura 2: Pruebas Saber $11^{\circ}$ : promedio lenguaje

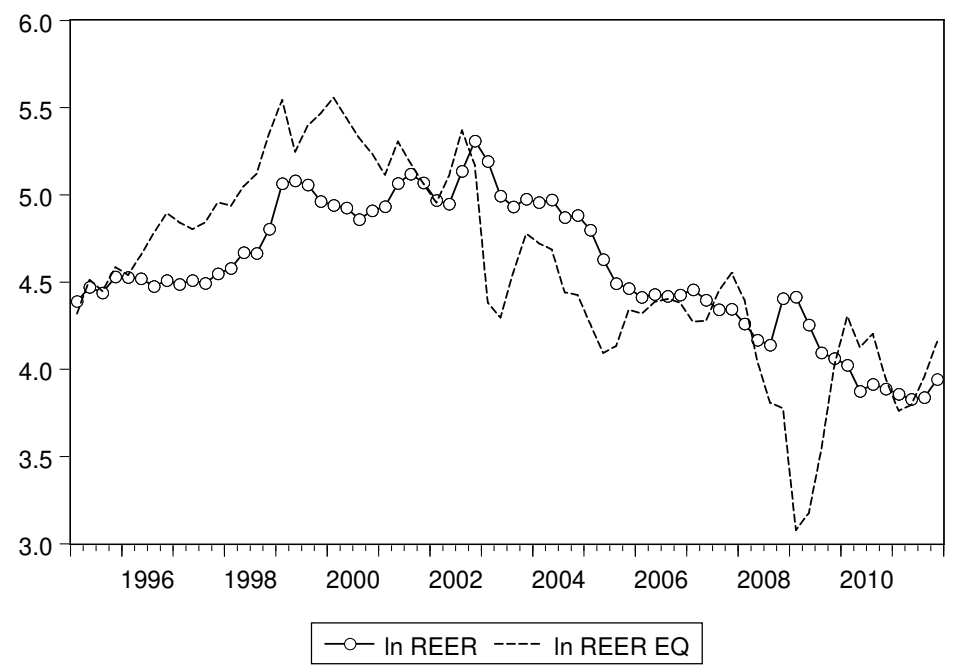

Fonte: Elaboração dos autores.

Figura 3: Desalinhamento corrente (\%) - sem DIFJUROS

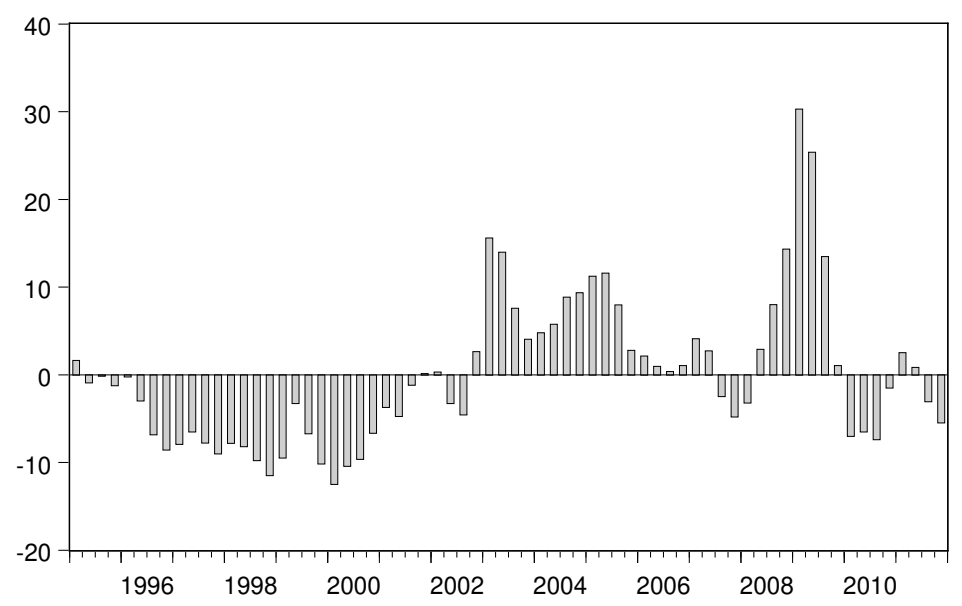

Fonte: Elaboração dos autores. 
Figura 4: Taxa de câmbio corrente e de equilíbrio - com DIFJUROS

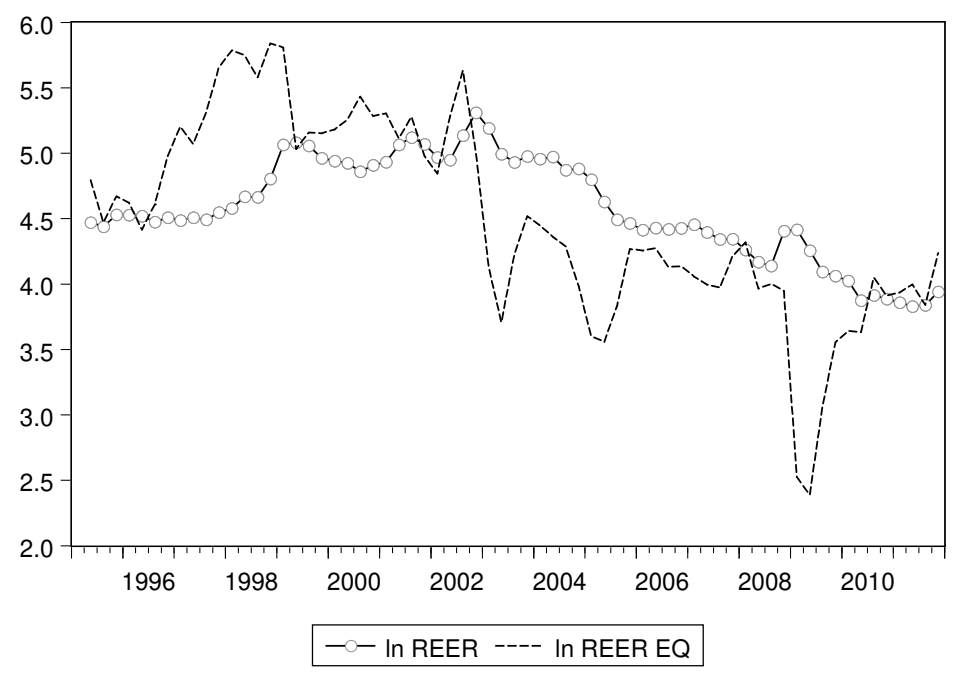

Fonte: Elaboração dos autores.

Figura 5: Desalinhamento corrente (\%) - com DIFJUROS

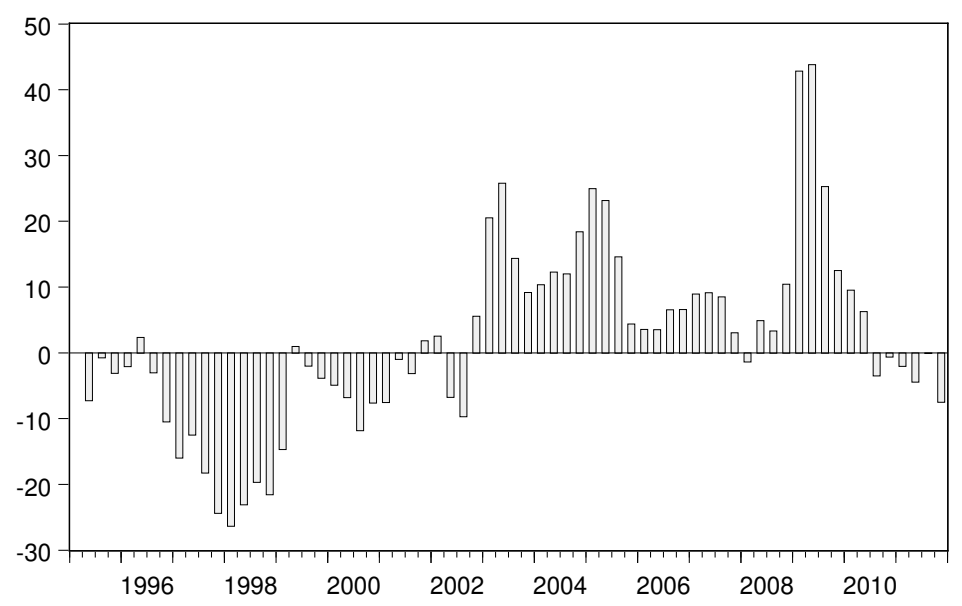

Fonte: Elaboração dos autores. 
pequena sobrevalorização cambial no ano $2011^{5}$.

Tabela 7: Desalinhamento corrente

\begin{tabular}{lr}
\hline \multicolumn{2}{c}{ Modelo sem DIFJUROS } \\
\hline Média 1995T3 a 1998T4 (Câmbio Rígido) & $-5,5 \%$ \\
Média Após 1999T1 (Câmbio Flexível) & $1,7 \%$ \\
Média Após 2008T3 (Crise Financeira) & $4,4 \%$ \\
Média 2011 & $-1,3 \%$ \\
\hline \multicolumn{2}{c}{ Modelo com DIFJUROS } \\
\hline Média 1996T1 a 1998T4 (Câmbio Rígido) & $-12,39 \%$ \\
Média Após 1999T1 (Câmbio Flexível) & $5,98 \%$ \\
Média Após 2008T3 (Crise Financeira) & $10,20 \%$ \\
Média 2011 & $-3,49 \%$ \\
\hline
\end{tabular}

\section{Desalinhamento Total}

Clark \& MacDonald (1999) e MacDonald (2000) argumentam que ao analisar o comportamento da taxa de câmbio real efetiva e fazer avaliações sobre a sustentabilidade da taxa de câmbio real efetiva, é importante verificar se os próprios fundamentos econômicos estão em seus valores sustentáveis ou de longo prazo. Como os valores correntes dos fundamentos econômicos podem ser distintos dos valores sustentáveis ou de longo prazo, é relevante calcular o desalinhamento total, que é a diferença entre o valor atual da taxa de câmbio real efetiva e a taxa de câmbio real efetiva dada pelos valores sustentáveis ou de longo prazo dos fundamentos econômicos.

A Figura 6 apresenta o comportamento da taxa de câmbio real efetiva corrente e da taxa de câmbio real efetiva de equilíbrio (fundamentos com filtro HP) obtida a partir da estimativa do VEC(1) para o modelo sem DIFJUROS e a Figura 7 apresenta o comportamento do desalinhamento cambial total associado. Os resultados apresentados sugerem: para o período $1995 \mathrm{~T} 3$ a $1998 \mathrm{~T} 4$ (câmbio rígido) o desalinhamento total médio foi de $-7,9 \%$, indicando sobrevalorização cambial; para o período após $1999 \mathrm{~T} 1$ (câmbio flexível) o desalinhamento total médio é de 3,2\%, indicando pequena subvalorização cambial; para o período após $2008 \mathrm{~T} 3$ (crise financeira) o desalinhamento total médio é de 5,0\%, indicando subvalorização cambial; e para 2011 o desalinhamento total médio é nulo indicando que a taxa de câmbio real efetiva se encontra em equilíbrio.

\footnotetext{
${ }^{5}$ Os autores calcularam o IPCA dos bens levando em consideração os preços livres de bens não duráveis, preços livres de semiduráveis e preços livres de bens duráveis, utilizando os seus respectivos pesos, sendo que a soma dos 3 pesos foi de $41,5 \%$, considerando que Serviços tem peso de $35,7 \%$ e Administrados/Monitorados tem peso de 22,8\%. Ao final foi obtido o IPCA Bens que não inclui a participação dos itens de Serviços e Administrados/Monitorados. A partir dos dados do IPCA Bens (sem Administrados/Monitorados e Serviços no IPCA) em substituição do IPCA original no cálculo da variável "Balassa-Samuelson (BS)" para captar o efeito Balassa-Samuelson, foi estimado um novo VEC com e sem o diferencial de juros e calculado o desalinhamento corrente da taxa de câmbio real efetiva. Os testes ADF, PP, KPSS e DF-GLS indicaram não estacionariedade da série LBS (IPCA Bens). O novo cálculo do desalinhamento corrente com LBS (IPCA Bens) indica que os desalinhamentos médios foram ainda menores nos quatro subperíodos analisados para os dois modelos com e sem o diferencial de juros, com exceção do ano de 2011 no qual o desalinhamento passou de $-1,3 \%$ para $-1,97 \%$ indicando uma maior apreciação cambial.
} 
A Figura 8 apresenta o comportamento da taxa de câmbio real efetiva corrente e da taxa de câmbio real efetiva de equilíbrio (fundamentos com filtro HP) obtida a partir da estimativa do VEC(2) para o modelo com DIFJUROS e a Figura 9 apresenta o comportamento do desalinhamento cambial total associado. As evidências apresentadas sugerem: para o período 1996T1 a 1998T4 (câmbio rígido) o desalinhamento total médio foi de $-17,2 \%$, indicando sobrevalorização cambial; para o período após 1999T1 (câmbio flexível) o desalinhamento total médio é de 7,4\%, indicando subvalorização cambial; para o período após $2008 \mathrm{~T} 3$ (crise financeira) o desalinhamento total médio é de $9,3 \%$, indicando subvalorização cambial; e para 2011 o desalinhamento total médio é de $-7,1 \%$, indicando sobrevalorização cambial.

Figura 6: Taxa de câmbio corrente e de equilíbrio - sem DIFJUROS

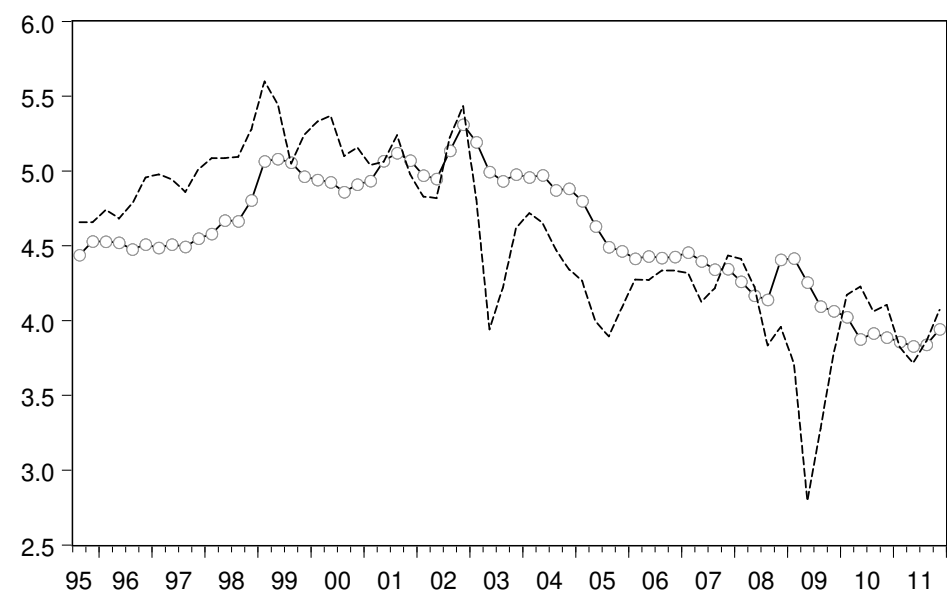

$-\circ-$ In REER ---- In REER EQ - Filtro HP

Fonte: Elaboração dos autores.

A Tabela 8 sintetiza os resultados apresentados para o comportamento do desalinhamento total considerando quatro subperíodos: o período de câmbio rígido, período de câmbio flutuante, período pós-crise do subprime e o ano 2011. Considerando o conceito de desalinhamento cambial total, os resultados apresentados sugerem a existência de sobrevalorização cambial durante $o$ período de câmbio rígido e no ano 2011.

\section{Considerações Finais}

Este trabalho tem como objetivo estimar a taxa de real efetiva de equilíbrio e o desalinhamento cambial para a economia brasileira utilizando dados para o período $1994 \mathrm{~T} 3$ a 2011T4. A trajetória da taxa de câmbio real efetiva brasileira tem sido objetivo de profícua discussão no âmbito dos formuladores de política, no meio acadêmico e empresarial em função da importância que a mesma exerce sobre o ajuste externo e a competitividade dos setores envolvidos no comércio internacional, além das possíveis consequências e impactos 
Figura 7: Desalinhamento total (\%) - filtro HP - sem DIFJUROS

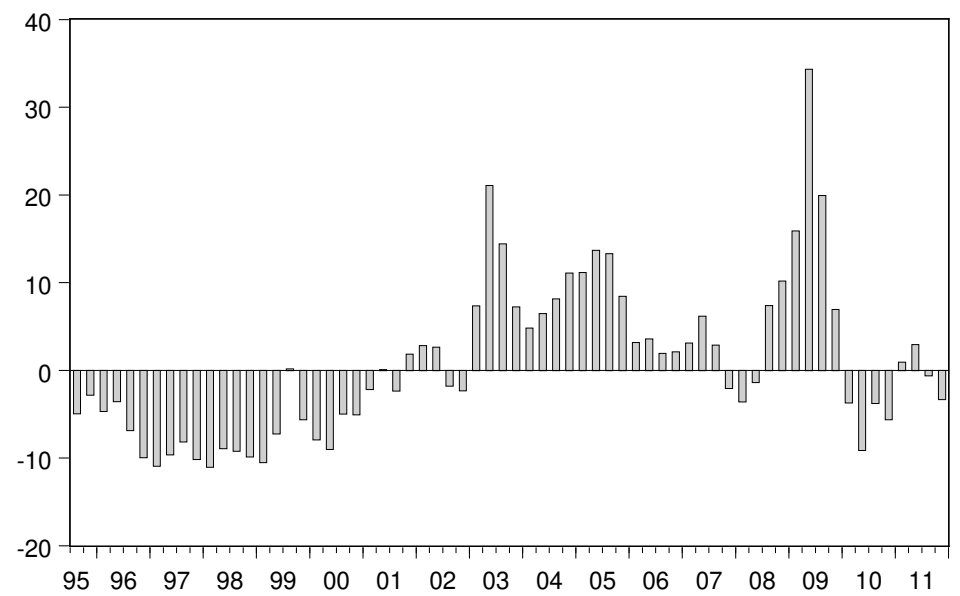

Fonte: Elaboração dos autores.

Figura 8: Taxa de câmbio corrente e de equilíbrio - com DIFJUROS

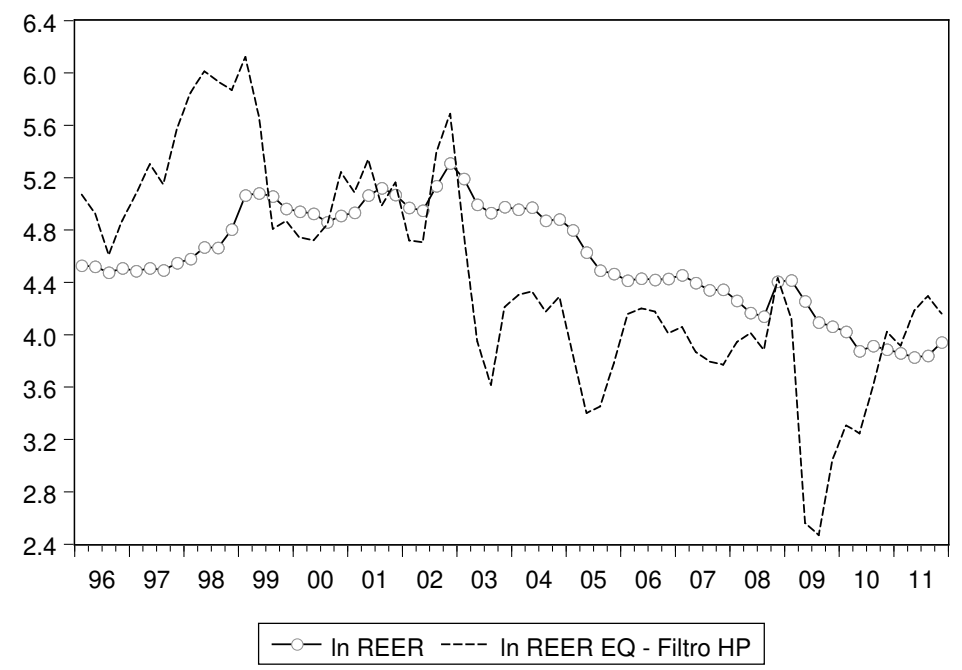

Fonte: Elaboração dos autores. 
Figura 9: Desalinhamento total (\%) - filtro HP - com DIFJUROS

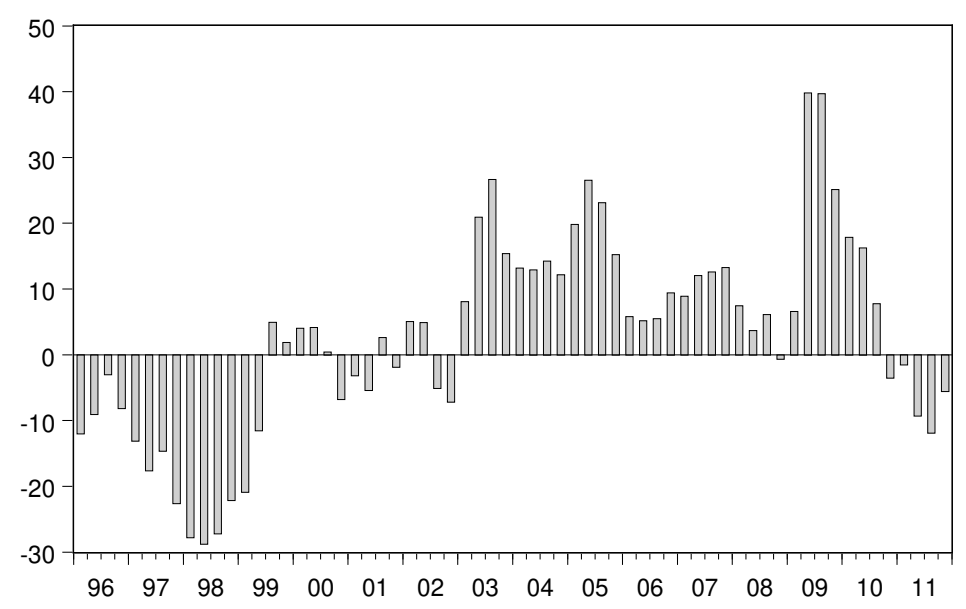

Fonte: Elaboração dos autores.

Tabela 8: Desalinhamento total

\begin{tabular}{lr}
\hline \multicolumn{2}{c}{ Modelo sem DIFJUROS } \\
\hline Média 1995T3 a 1998T4 (Câmbio Rígido) & $-7,9 \%$ \\
Média Após 1999T1 (Câmbio Flexível) & $3,2 \%$ \\
Média Após 2008T3 (Crise Financeira) & $5,0 \%$ \\
Média 2011 & $-0,0 \%$ \\
\hline \multicolumn{2}{c}{ Modelo com DIFJUROS } \\
\hline Média 1996T1 a 1998T4 (Câmbio Rígido) & $-17,2 \%$ \\
Média Após 1999T1 (Câmbio Flexível) & $7,4 \%$ \\
Média Após 2008T3 (Crise Financeira) & $9,3 \%$ \\
Média 2011 & $-7,1 \%$ \\
\hline
\end{tabular}

sobre o setor industrial brasileiro. Portanto, justifica-se a utilização de arcabouço empírico adequado para avaliar se trajetória da taxa de câmbio real efetiva implica em desvios em relação ao equilíbrio ou reflete um fenômeno de equilíbrio.

O trabalho utiliza o conceito de taxa de câmbio de equilíbrio comportamental (BEER) e contribui para a literatura empírica brasileira em três aspectos: i) constrói a série de taxa de câmbio real efetiva considerando os 20 principais parceiros comerciais; ii) os determinantes da taxa de câmbio real efetiva são calculados em relação àqueles dos 20 principais parceiros comerciais; iii) calcula uma medida de desalinhamento corrente e uma medida de desalinhamento total. A apresentação dos resultados foi organizada para quatro subperíodos: 1994T3 a 1998T4, período durante o qual vigorou regime de câmbio rígido; $1999 \mathrm{~T} 1$ a 2011T4, período durante o qual vigora o regime de câmbio flexível; 2008T3 a 2011T4, período pós-crise do subprime; e o ano 2011, período mais recente.

Utilizando o conceito de desalinhamento cambial corrente e considerando 
os dois modelos estimados os resultados indicam: desalinhamento corrente médio de $-5,5 \%$ e $-12,39 \%$ durante o período $1994 \mathrm{~T} 3$ a $1998 \mathrm{~T} 4,1,7 \%$ e $5,98 \%$ durante o período $1999 \mathrm{~T} 1$ a $2011 \mathrm{~T} 4,4,4 \%$ e $10,2 \%$ durante o período $2008 \mathrm{~T} 3$ a $2011 \mathrm{~T} 4,-1,3 \%$ e $-3,49 \%$ em 2011 . Utilizando o conceito de desalinhamento cambial total e considerando os dois modelos estimados, as evidências sugerem: desalinhamento total médio de $-7,9 \%$ e $-17,2 \%$ durante o período $1994 \mathrm{~T} 3$ a $1998 \mathrm{~T} 4,3,2 \%$ e $7,4 \%$ durante o período $1999 \mathrm{~T} 1$ a $2011 \mathrm{~T} 4,5,0 \%$ e 9,3\% durante o período $2008 \mathrm{~T} 3$ a $2011 \mathrm{~T} 4,-0,0 \%$ e $-7,1 \%$ em 2011 . Portanto, para os conceitos de desalinhamento corrente e total, há evidência de sobrevalorização cambial durante a vigência do regime de câmbio rígido e no período mais recente (2011). É oportuno contextualizar as evidências apresentadas neste trabalho com as reportadas na literatura brasileira:

i) As evidências apresentadas neste trabalho sobre a existência de sobrevalorização cambial no período durante o qual vigorou o regime de câmbio rígido são coerentes com as evidências reportadas por IEDI (2007), Araujo \& Leite (2009), Pastore et al. (2010) e Marçal (2011). Badani \& Hidalgo (2005) reportam a inexistência de desalinhamento cambial, e os resultados reportados por Paiva (2006) sugerem a alternância entre períodos de sobrevalorização cambial e subvalorização cambial. Portanto, para o período de câmbio rígido, a literatura não é consensual, embora a maioria dos trabalhos indique a existência de sobrevalorização cambial;

ii) Para o período de câmbio flexível, os resultados apresentados neste trabalho em geral sugerem a existência de subvalorização cambial no período de $2002 \mathrm{~T} 4$ a $2010 \mathrm{~T} 3$ e sobrevalorização cambial modesta no período de 2010T4 a 2011T4. Esses resultados são distintos dos apresentados na literatura: Paiva (2006) sugere a ausência de desalinhamento cambial no período de 2003 a 2005 e Pastore et al. (2010) no período de jan/2003 a nov/2009; IEDI (2007) sugere a existência de sobrevalorização cambial no período de 2005T1 a 2006T4, Lucinda \& Gala (2007) no período de jul/2005 a ago/2006, Araujo \& Leite (2009) no período de 2005T1 a $2007 T 3$ e Marçal (2011) no período de 2005T3 a 2010T4.

Ao contrário do sugerido pelos trabalhos consultados, as evidências apresentadas neste trabalho não corroboram a existência de sobrevalorização cambial para o período recente, exceto a partir de meados de 2010 e em pequena magnitude. Uma possível explicação para a distinção entre os resultados apresentados neste trabalho e os reportados na literatura brasileira sobre o tema, especialmente para o período recente, pode ser a abordagem metodológica adotada neste trabalho, a qual permite um cálculo acurado da taxa de câmbio de equilíbrio e do desalinhamento cambial, cabendo destacar o conceito de taxa de câmbio e sua mensuração, os fundamentos e sua mensuração, o método econométrico e o modelo teórico subjacente, a abordagem comportamental da taxa real de câmbio (BEER).

Ademais, os resultados apresentados neste trabalho sugerem a importância das variáveis Balassa-Samuelson e Ativo Externo Líquido (modelo VEC, estimado sem diferencial de juros) e as variáveis Balassa-Samuelson, Dívida Pública e Termos de Troca (modelo VEC, estimado com diferencial de juros) para o comportamento da taxa de câmbio real efetiva. Um aumento da razão entre o preço dos bens não comercializáveis e preço dos bens comercializáveis, uma melhora nos termos de troca e um aumento da dívida pública 
levam a uma apreciação cambial de equilíbrio, ao passo que um aumento no ativo externo líquido leva a uma depreciação cambial de equilíbrio. O comportamento dos termos de troca e do ativo externo líquido estão em alguma medida associados a fatores externos (comércio e finanças internacionais).

Esses resultados têm implicações normativas importantes: i) considerando a participação de preços administrados no IPCA, a política governamental de reajuste de preços administrados pode influenciar a razão entre o preço dos bens não comercializáveis e preço dos bens comercializáveis e, portanto, a trajetória da taxa de câmbio real efetiva de equilíbrio; ii) a política fiscal molda a trajetória da dívida pública e, portanto, pode influenciar o comportamento da taxa de câmbio real efetiva de equilíbrio; iii) a política monetária pode influenciar a trajetória da dívida pública, considerando que parte da dívida pública é atrelada à SELIC e a índices de preços e, portanto, pode influenciar a trajetória da taxa de câmbio real efetiva de equilíbrio. Portanto, políticas que alterem os fundamentos que determinam a taxa de câmbio real efetiva podem corrigir eventual desalinhamento cambial, não havendo justificativa para intervenções da autoridade monetária na liquidez do mercado com esse fim.

\section{Agradecimento}

Os autores agradecem o apoio financeiro do CNPq e da FAPEMIG.

\section{Referências Bibliográficas}

Alberola, E., Lopez, H., Ubide, A. J. \& Cervero, S. G. (1999), Global equilibrium exchange rates: Euro, Dollar, 'ins', 'outs', and other major currencies in a panel cointegration framework. International Monetary Fund, Working Paper 175.

Araujo, E. C. \& Leite, M. V. C. (2009), Sobreapreciação cambial no Brasil: estimativa, causas e consequências (1994-2008). Instituto de Pesquisa Econômica Aplicada (IPEA), Texto para Discussão 1404.

Badani, P. C. \& Hidalgo, Á. B. (2005), 'A taxa de câmbio real de equilíbrio no Brasil', Economia Aplicada 9(4), 543-555.

Banco Central do Chile (2013), 'Banco Central do Chile', Disponível em: http://www.bcentral.cl/index.asp.

URL: http://www.bcentral.cl/index.asp

Bénassy-Quéré, A., Lahrèche-Révil, A. \& Mignon, V. (2011), 'Worldconsistent equilibrium exchange rates', Journal of the Japanese and International Economies 25(2), 12-32.

Beveridge, S. \& Nelson, C. R. (1981), 'A new approach to decomposition of economic time series into permanent and transitory components with particular attention to measurement of the "business cycle", Journal of Monetary Economics 7(2), 151-174.

Chen, J. (2009), 'Beyond cheap talks: assessing the undervaluation of the Chinese currency between 1994 and 2007', Économie Internationale 119(3), 4782. 
China Statistical Yearbook (2013), 'National Bureau of Statistics of China', Disponível em: http://www.stats.gov.cn/english/statisticaldata/ Quarterlydata/.

URL: $h t t p: / / w w w . s t a t s . g o v . c n / e n g l i s h / s t a t i s t i c a l d a t a / Q u a r t e r l y d a t a /$

Clark, P. B. \& MacDonald, R. (1999), Exchange rates and economic fundamentals: a methodological comparison of BEERs and FEERs, in R. MACDONALD \& J. L. STEIN, eds, 'Equilibrium exchange rates', Springer, pp. 285322.

Clark, P. B. \& MacDonald, R. (2004), 'Filtering the BEER: a permanent and transitory decomposition', Global Finance Journal 15(1), 29-56.

Cline, W. R. \& Williamson, J. (2012), 'Updated estimates of fundamental equilibrium exchange rates', Peterson Institute for International Economics PB14, 1-13.

Égert, B., Halpern, L. \& MacDonald, R. (2006), 'Equilibrium exchange rates in transition economies: taking stock of the issues', Journal of Economic Surveys 20(2), 257-324.

Enders, W. (2004), Applied Econometric Times Series: And Rats Handbook for Econometric Time Series, 2 edn, John Wiley \& Sons.

European Central Bank (2013), 'Estatísticas do Banco Central Europeu', Disponível em: http://www.ecb.int/stats/html/index.en.html.

URL: $h t t p: / / w w w . e c b . i n t / s t a t s / h t m l / i n d e x . e n . h t m l$

Faruqee, H. (1995), 'Long-run determinants of the real exchange rate: a stockflow perspective’, Staff Papers 42(1), 80-107.

Faruqee, H., Isard, P. \& Masson, P. R. (1999), A macroeconomic balance framework for estimating equilibrium exchange rates, in R. Macdonald \& J. L. Stein, eds, 'Equilibrium exchange rates', Springer, pp. 103-133.

Hodrick, R. J. \& Prescott, E. C. (1997), 'Postwar US business cycles: an empirical investigation', Journal of Money, Credit, and Banking 29(1), 1-16.

IEDI (2007), 'Estimando o desalinhamento cambial para a economia brasileira', Instituto de Estudos para o Desenvolvimento Industrial pp. 1-24.

IMF (2013a), Direction of Trade Statistics, IMF, Washington, D.C.

IMF (2013b), Historical Public Debt Database, IMF, Washington, D.C.

IMF (2013c), International Financial Statistics, IMF, Washington, D.C.

IMF (2013d), World Economic Outlook Database, IMF, Washington, D.C.

Isard, P. (2007), Equilibrium Exchange Rates: Assessment Methodologies. IMF Working Paper 296.

Isard, P. \& Faruqee, H. (1998), Exchange rate assessment: extension of the macroeconomic balance approach. IMF Occasional Papers 167.

Johansen, S. (1988), 'Statistical analysis of cointegration vectors', Journal of Economic Dynamics and Control 12(2-3), 231-254. 
Johansen, S. (1995), Likelihood-based Inference in Cointegrated Vector Autoregressive Models, Oxford University Press on Demand.

Kakkar, V. \& Ogaki, M. (1994), Real exchange rates and non-tradables. University of Rochester, Rochester Center for Economic Research 379.

Lane, P. R. \& Milesi-Ferretti, G. M. (2007), 'The external wealth of nations mark II: revised and extended estimates of foreign assets and liabilities, 1970-2004', Journal of International Economics 73(2), 223-250.

Lucinda, C. R. \& Gala, P. (2007), Desalinhamento cambial no Brasil após o Plano Real: uma análise empírica. Texto para Discussão da Escola de Economia de São Paulo da Fundação Getúlio Vargas 167.

MacDonald, R. (2000), Concepts to calculate equilibrium exchange rates: an overview. Economic Research Group of the Deustche Bundesbank, Discussion Paper n. 3.

MacDonald, R. \& Dias, P. (2007), Behavioural equilibrium exchange rate estimates and implied exchange rate adjustments for ten countries. University of Glasgow, Discussion Paper 10.

MacKinnon, J. G., Haug, A. A. \& Michelis, L. (1999), 'Numerical distribution functions of likelihood ratio tests for cointegration', Journal of Applied Econometrics 14(5), 563-577.

Marçal, E. F. (2011), Estimando o desalinhamento cambial brasileiro a partir de modelos multivariados com cointegração. Instituto de Pesquisa Econômica Aplicada (IPEA), Texto para Discussão 1666.

OECD (2013), 'OECD statistics', Disponível em: http: //stats .oecd.org/.

URL: http://stats.oecd.org/

Paiva, C. (2006), External adjustment and equilibrium exchange rate in Brazil. International Monetary Fund, Working Paper 221.

Pastore, A. C., Pinotti, M. C., Pagano, T. A. et al. (2010), 'Limites ao crescimento econômico', Fórum Nacional .

Perron, P. (1989), 'The great crash, the oil price shock, and the unit root hypothesis', Econometrica 57(6), 1361-1401.

Perron, P. (1997), 'Further evidence on breaking trend functions in macroeconomic variables', Journal of Econometrics 80(2), 355-385.

Rogoff, K. (1996), 'The purchasing power parity puzzle', Journal of Economic Literature 34(2), 647-668.

Stein, D. (1994), 'The natural real exchange rate of the US Dollar and determinants of capital flows', Institute for International Economics .

Stein, J. L. (1995), The fundamental determinants of the real exchange rate of the US Dollar relative to other G-7 currencies. International Monetary Fund, Working Paper 81.

Stein, J. L. (2002), 'The equilibrium real exchange rate of the Euro: an evaluation of research', CESifo Economic Studies 43(3), 349-381. 
Taylor, A. M. \& Taylor, M. P. (2004), 'The purchasing power parity debate journal of economic perspectives, 18', Journal of Economic Perspectives 18, 135-158.

Williamson, J. (1983), The Exchange Rate System, number 5 in 'Policy Analyses in International Economics', Peterson Institute for International Economics, Washington, D.C.

Williamson, J. (1994), Estimates of feers, in J. Williamson, ed., 'Estimating Equilibrium Exchange Rates', Institute for International Economics Banco Central do Chile, Washington, D.C., pp. 177-245.

World Bank (2013), 'World development indicators', Disponível em: http: / / data. worldbank .org/data-catalog/world-development-indicators/wdi-2013. URL: http://data.worldbank.org/data-catalog/world-developmentindicators/wdi-2013

Zivot, E. \& Andrews, D. W. K. (2002), 'Further evidence on the great crash, the oil-price shock, and the unit-root hypothesis', Journal of Business E Economic Statistics 20(1), 25-44. 